\title{
Cycled-Simple Environmental Condition
}

National Cancer Institute

\section{Source}

National Cancer Institute. Cycled-Simple Environmental Condition. NCI Thesaurus. Code C134027.

A set of two alternating environmental conditions. 